\title{
Ergonomic Program and Nursing Intervention in Nursing Students
}

\author{
Ni Ketut Guru Prapti ${ }^{1}$, Putu Oka Yuli Nurhesti ${ }^{2}$, Ketut Tirtayasa ${ }^{3}$ \\ Nursing Department, \\ Faculty of Medicine, Udayana University, \\ Jimbaran \\ E-mail: prapti.nkg@unud.ac.id \\ Nursing Department, \\ Faculty of Medicine, Udayana University, \\ Jimbaran \\ Physiology Department, \\ Faculty of Medicine, Udayana University, \\ Jimbaran
}

\begin{abstract}
Ergonomics position is the position that should be done while working on a such procedure to improve work security, work efficiency and reduce risk factors. Nurses are the health workers with the biggest exposure risk factor. The results of the preliminary study showed that more than 50 percent of the students are still doing the wrong position when performing nursing interventions. This study was conducted at Nursing Study Program of Udayana University wich aims to know the effect of comprehensive ergonomic program on ergonomic position of students when performing nursing interventions. A quasy experimental design with action research application was used to analyze the effect of an ergonomic program on knowledge, attitude and behavior of nursing students. Nursing students of Udayana University was the population of this study and simple random sampling techniques was used with sample size of 50 respondents. Evaluation of this study were involves the readiness of institutions to apply programs and modifications according to institutional conditions. The results showed that there is a significant effect of ergonomic program on student's knowledge, attitude and behavior related to ergonomic standard in performing nursing interventions with statistic test result $\mathrm{p}<0,05$. Student behavior can be improved by increasing the students' knowledge on the ergonomic position when performing nursing intervention. Based on the results of this study, the institute is expected to provide knowledge about the importance of ergonomics position to nursing students, either through counseling or by incorporating into one of the subjects in the nursing curriculum.
\end{abstract}

Index Terms - ergonomic program, nursing student and nursing intervention

\section{INTRODUCTION}

Standard ergonomic position is the position that should be applied while working or during implementing a procedure in order to improve safety, work efficiency, and reduce risk factors due to work[1]. Health personnel are vulnerable for various work-related risk factors, including incorrect working positions; and nurses have the highest risk for the unergonomic working position. Various nursing procedures, such as wound care, manage fluid balace (infusion), inserting catheter and others, are procedures requiring standard ergonomic positions to prevent nurses from various health risks due to improper work positions[1][2].

In the United States nurses with musculoskeletal disorders incidence is 252 per 10,000 nurses, this incidence rate is more than 7 times in the same nurse. The incidence of injury among nurses reached 56\% in 2006 and $86 \%$ of those incidences were injury associated with excessive stretching positions[3]. Rahayu[4] explains on her research results at Serang Banten Hospital that nurses working with 
three working shiftness which are morning, afternoon and evening shift have a risk of MSDs. Nursing activities with the hightest risk of improper working positions are generaly applied during morning shift. Several nursing interventions with highest risk for MSDs are bathing, lifting, wound dressing, changing the patient's position, and taking urine measurements. A study conducted by Fathoni et al[5] in Purbalingga Hospital showed that $31.2 \%$ of nurses are performing nursing procedures with non-ergonomic positions.

Nursing students learn the skills needed to become professional nurses. The learning process include academic and professional stage. There are more less 48 skills that nursing students learns during academic stage such as; wound care, catheter insertion, patient transfer, infusion setting and others. These skills are learned using human dummy or peer practical partners.

Based on the results of preliminary study in Nursing Science Program, Faculty od Medicine Udayana University, 7 out of 10 students still bent during the practice of wound care. Moreover, there were 8 out of 10 students who were performing non-ergonomic postions during bandage intervention, which potentially risk on back problems. Six out of 10 students performed patient transfer positions with non ergonomic working positions. According to Gurgueira et al[6], working positions and procedures, which are not applied with standar ergonomic, could potentially cause physical, psychological and psychosocial disorders to nurses. The improper positions, attitudes and work procedures which are becoming habit as students could be be carried away until these nursing students becoming profesionals nurses. Ergonomic positions are generally taught in Nursing Science Program, Faculty of Medicine Udayana University; however, the correct ergonomic positions have not yet been thoroughly practiced and are less empahised as important aspects during learning process of nursing skills.

Ergonomic program is an intervention applied to nursing students to improve the safety and work effectiveness, and to prevent various risks of health problems, especially musculoskeletal disorders. A study conducted by Garg and Kapellusch[7] shows that the ergonomic program could reduce the risk factors for injury due to the improper position and incorrect work attitude from $24.4 \%$ to $9.8 \%$.

Ergonomic program can be an effective primary prevention of physical and psychological health problems that may occur due to improper working positions, attitudes and working procedures. This program has been applied by making technological innovations through audiovisual media as well as provision of facilities that support work using standard ergonomics. This program is generally needed by various health professionals; such as nurses, doctors, physiotherapists, dentists in others. Providing and modification of work facilities and working procedures will support nurses and nursing students to perform safe, effective and efficient working procedures.

The aim of this research is to analyse the effect of standard ergonomic comprehensive intervention on implementation of ergonomic position among nursing students while performing nursing interventions. The specific purpose of this study is to discover the standard ergonomic description of the students while performing nursing procedures before comprehensive intervention, providing a comprehensive understanding of the importance of ergonomic position in performing nursing procedures on students as prospective nurses, to assess the description of standard ergonomic position applied by students after comprehensive intervention. The analysis was be conducted to assess the readiness of nursing students as prospective nurses in performing nursing procedures with standard ergonomic positions. The readiness of the Nursing Science Program Faculty of Medicine Udayana University is also assessed in supporting the implementation of ergonomic program as one of the technological innovation of the study program.

\section{METHOD}

This research is quasy experimental study with action research application to analyze the influence of ergonomic program to the knowledge, attitude and behavior of standard ergonomic of nursing students while performing nursing procedures. Evaluation involves the readiness of institutions in implementing the program, the provision of appropriate support facilities and environmental setting suitable for institutional conditions based on ergonomic standard. Subjects of this study are nursing students in Nursing Science Program Faculty of Medicine Udayana University. The instruments used on this study are questionnaire and observation sheet.

Researchers have considered ethical principles while conducting of any actions or interventions in this study, and all activities performed on study subjects have been approved with clear informed consent. Prior to the research, ethical clearance was reviewed by research ethics committee of Faculty of Medicine Udayana University / Sanglah Hospital Denpasar.

\section{RESULT}

The study was conducted in September 2016. The data gathered in the treatment group and control group was collected at the nursing lab skill. Only 50 from 76 students can be analyzed using REBA both in the treatment group and in the control group. Based on the results of data collection in the treatment group and the control group found that the students do not have adequate understanding about the ergonomic position while performing nursing intervention. This study results are depicted below

\section{A. Respondent Characteristics}

Respondent characteristics by age and gender. Based on 
table 1, it can be seen that age of respondents of treatment group is mostly 20 years, which are 37 respondents (74\%); while in the age control group most respondents were at the age of 21 years as many as 39 respondents (78\%) and only 1 respondent $(2 \%)$ aged 23 years. The respondents' gender both in the treatment and the control group was dominated female. The number of female respondents in the treatment group were 50 respondents (100\%), while in the control group the number of female respondents were 41 (82\%). Respondent characteristics by age and gender can be seen in the following table:

Table 1. Respondent characteristics by age and gender

\begin{tabular}{|c|c|c|c|c|c|}
\hline \multicolumn{3}{|c|}{ Data of treatment group } & \multicolumn{3}{|c|}{ Data of control group } \\
\hline Characteristics & $\sum$ & $\%$ & Characteristics & $\sum$ & $\%$ \\
\hline Age & & & Age & & \\
\hline 19 & 3 & 6.0 & 19 & - & 0 \\
\hline 20 & 37 & 74.0 & 20 & 2 & 4.0 \\
\hline 21 & 10 & 20.0 & 21 & 39 & 78.0 \\
\hline 22 & - & 0 & 22 & 8 & 16.0 \\
\hline 23 & - & 0 & 23 & 1 & 2.0 \\
\hline Total & 50 & 100 & Total & 50 & 100 \\
\hline Gender & & & Gender & & \\
\hline Male & 0 & 0 & Male & 9 & 18.0 \\
\hline Female & 50 & 100 & Female & 41 & 82.0 \\
\hline Total & 50 & 100 & Total & 50 & 100 \\
\hline
\end{tabular}

\section{B. Ergonomic Standard in the Treatment Group and Control Group}

The ergonomics standard performed by the subjects when performing the nursing procedures assessed by REBA score in the treatment and control group can be seen in the following table:

Table 2. Ergonomic Standard based on REBA score

\begin{tabular}{ccccc}
\hline $\begin{array}{c}\text { REBA } \\
\text { score }\end{array}$ & \multicolumn{2}{c}{ Treatment group } & \multicolumn{2}{c}{ Control group } \\
\cline { 2 - 5 } 1 & 3 & 6 & value & $\%$ \\
$2-3$ & 17 & 34 & 0 & 0 \\
$4-7$ & 20 & 40 & 7 & 0 \\
$8-10$ & 8 & 16 & 28 & 56 \\
$11-15$ & 2 & 4 & 15 & 30 \\
\hline & 50 & 100 & 50 & 100 \\
\hline
\end{tabular}

Based on table 2 can be seen that REBA scores of students while performing nursing procedures in the treatment group was mostly on the score of 4-7, which are 20 respondents $(40 \%)$. In the control group most of the respondents are on the score of 8- 10 of 28 respondents (56\%).

\section{Different Test Results of REBA Score on Treatment Group and Control Group}

Statistical analysis is used Man Whitney U Test

Table 3. Different Test Results REBA Score on Treatment Group and Control Group

\begin{tabular}{lcc}
\hline Ergonomic Standar & $\begin{array}{c}\text { Mean of REBA } \\
\text { score }\end{array}$ & $p$ \\
\hline Treatment group & 29.24 & 0.000 \\
Control group & 71.76 & \\
\hline
\end{tabular}

Based on table 3 it can be seen that the value of $p=$ 0.000 , this value is smaller than 0.05 which means there is a significant difference of ergonomic standards in the treatment group and control. The mean REBA scores between the treatment and control groups were 29.24 and 71.76 , respectively. These results suggest that providing a comprehensive information of the importance of ergonomic positions in performing nursing procedures to nursing students can improve students' knowledge and attitudes toward the application of ergonomic positions during nursing interventions.

\section{DISCUSSION}

\section{A. Characteristics of Respondents}

On the characteristics of respondents by age, the average age of respondents in the treatment group and control group were 20 and 21 years respectively. The youngest age in the treatment group was 19 years and the oldest age was 21 years; while in the control group, the youngest age was 20 years and the oldest age was 23 years. Majority the treatment group is 20 years old, which is 37 respondents (74\%); while the control group majority is 21 years, which is 39 respondents $(78 \%)$. As subjects mostly are chategorised young adult, it means that psysichally their muscle are still good in flexibility, contraction, reflexes and excitatory excitability. The respondents' gender between both groups is mostly female. In the treatment group the number of female respondents were all 50 respondents $(100 \%)$ while in the control group the number of female respondents was $41(82 \%)$. Men and women have the same risk of low back pain[8], but in fact one's gender may experience different onset of back pain.

\section{B. Ergonomic Standard of the Treatment Group and Control Group}

Ergonomic standard is assessed between treatment and control group using REBA score. The REBA scores in the treatment group mostly on the score of 4-7 were as many as 20 respondents (40\%) while in the control group most of the respondents were on score 8- as many as 28 respondents $(56 \%)$. This result indicates that there are differences attitude when performing nursing procedures between the treatment group and the control group.

Center for Health and Occupational Safety of the Ministry of Health of the Republic of Indonesia (2008), states that the scope of ergonomics covers several aspects of science, namely: engineering, physical, anatomy, anthropometry, physiology and design. Techniques are important to be considered in performing nursing procedures, the supporting technique in performing nursing 
intervention could prevent health injuries. Another important thing to note is design, the setting of design workplace supports properly, safely and comfortably works.

Working attitude defines how the body position, head, hands and feet cooperation in working. The purpose of applying a good ergonomic behavior is improving the productivity of labor in a workplace. A monotonous work attitude such as sitting or standing can cause discomfort. Standing position for long periods tend to try to balance their body position, this may affect static workload on the back muscles and legs so that will increase blood retension on the lower limbs.

\section{Different Test Results of REBA Score on Treatment Group and Control Group}

Statistical analysis using Mann withney $\mathrm{u}$ test test resulted $\mathrm{p}=0.000$, this value is smaller than 0.05 ; thus, it can be concluded that there are significant difference of ergonomic standard in treatment group and control group. The mean REBA scores between the treatment and control groups were 29.24 and 71.76 , respectively. These results suggest that providing a comprehensive understanding of the importance of ergonomic positions in performing nursing procedures in nursing students can improve students' knowledge and attitudes in the application of ergonomic positions during nursing interventions.

In line with a study conducted by Garg and Kapellusch[9] which shows that the ergonomics program can reduce the risk factors for injury due to improper working position and attitude. It is explained that the ergonomic program can improve the behavior of nurses while performing nursing procedures in accordance with standard ergonomics. Various studies have shown that nursing procedures performed with non-ergonomic positions are increasing the risk of injuries among nurses[10][11]. Nursing procedures having risk of health problems include; monotonous positions, lifting patients, transferring patients, and performing wound care.

Granjean[4] recommends several workplace settings. His recommendation includes setting of working tables based on different type of works. The type of work that requires high precision in standing position, the height of the table is recommandably set $10 \mathrm{~cm}$ above the elbow. The height of the table is set parallel to the elbow height is recommended for light work; and for heavy work, the location of the height of the table is set $10 \mathrm{~cm}$ below the height of the elbow [4]. Wound care and chateter infusion insertion are the example of nursing interventions, which need high precision and performing by nurses in standing position. Based on Guardian study it is recommended that the hight of patient bed or the working table is $10 \mathrm{~cm}$ above the nurse's ebow hight while performing nursing interventions needed high concentration and standing position such as wound care.

Working in a sitting position has advantages including reducing on foot loading, energy consumption and the blood circulation demand [4]. Sitting position can be recommende for several nursing procedures required long time concentration, such as vital signs observation, intra venous chateter insertion or other nursing procedures that can be performed by sitting. The benefit of working by sitting is reducing fatigue, avoiding unnatural attitudes, decreasing energy consumption, reducing blood circulation demand [4]. However, if the sitting position is not performed properly it can increase the pressure on the spine [4].

Ergonomic program is a program that benefit on preventing health problems that may arise due to work and on helping nurses and nursing students in performing nursing procedures with ergonomic standard. Various ergonomic programs can be applied to prevent health problems on nurses. The Ergonomic programs can include workplace environment analysis, occupational hazards prevention and control, management of health services, education and training on standard ergonomic positions [12]. Moreover, the ergonomic program can also include training about methods of transfer of patients with standard ergonomic position and dissemination about using tools which can reduce musculoskeletal injuries in nurses [13][14].

\section{CONCLUSION}

Based on the results of this study, it can be concluded that the majority of respondents in the treatment group showed good working attitude and working position while performing nursing procedures. Additionally, there was a significant difference between treatment groups given a comprehensive understanding of the importance of ergonomic positions in performing nursing procedures compared to control group who were not exposed to information about the importance of ergonomic positions when performing nursing procedures.

\section{REFERENCES}

[1] Bandeiraa. M. G., Dinizb R.L., and Sardinhac A, H., "Ergonomic constraints among nursing workers in the sectors of emergency care in two public hospitals in Brazil”, IOS Press, 2012.

[2] Smith, Derek R., et al., "Examining the Dimensions of Hospital Safety Climate and Psychosocial Risk Factors Among Japanese Nurses", Journal of Transcultural Nursing 22, 2011.

[3] Bureau of Labor Statistics., "Nonfatal occupational injuries and illnesses requiring days away from work", 2007. News (USDL-081716). Washington, DC: U.S. Department of Labor.

[4] Sri Rahayu., “Analisis Risiko Ergonomi pada Pekerjaan Perawat Terhadap Kemungkinan Timbulnya Musculoskeletal Disorders Akibat Postur Janggal di Unit ICU”, Rumah Sakit Umum Serang, Banten, 2004.

[5] Fathoni H., Handoyo, Swasti K.H., "Hubungan Sikapdan Posisi Kerjadengan Low Back Pain Pada Perawat di RSUD Purbalingga. Jurnal Keperawatan, Volume 4, No.3, 2009.

[6] Gurgueira G.P., Alexandre N.M.C., Filho H.R.C., "Prevalence of musculoskeletal symptoms in nursing", Latin American journal of nursing, 2003.

[7] Garg, A. and Kapellusch, J.M., "Long-Term Efficacy of an Ergonomics Program That Includes Patient-Handling Devices on Reducing Musculoskeletal Injuries to Nursing Personnel”. Vol. 54, No. 4, 2012. 
[8] Ackley, B.J., Ladwig, G.B., Swan, B.A., \& Tucker, S.J., "Evidencebased nursing care guidelines: Medical-surgical interventions St. Louis", Mosby, 2007.

[9] Garg, A. and Kapellusch J.M., "Long-Term Efficacy of an Ergonomics Program That Includes Patient-Handling Devices on Reducing Musculoskeletal Injuries to Nursing Personnel", Human Factors Vol. 54, No. 4, 2012.

[10] Lemo A., Silva A.G., Tucherman M., Talerman C., Guastelli R.L. e Borba C.L. "Risk reduction in musculoskeletal practice assistance professional nursing pilot in semi intensive care unit", IOS Press, 2012.

[11] Özarslan A., "The frequency of occupational accidents among the nurses working in a training hospital in Ankara, Health Sciences Institute of Gazi University, Department of Demography and Epidemiolojy of Accidents", Master Thesis, 2009.

[12] Bandeiraa. M.G., Dinizb R.L. and Sardinhac A.H., "Ergonomic constraints among nursing workers in the sectors of emergency care in two public hospitals in Brazil.", IOS Press, 2012.

[13] Schibye, B., Faber Hansen, A., Hye-Knudsen, C.T., Essendrop, M., Bocher, M., \& Skotte, J., "Biomechanical analysis of the effect of changing patient-handling technique.", Applied Ergonomics, 2003.

[14] Smeltzer, S. C., Bare, B.G., Hinkle, J.L., \& Cheever, K..H., "Brunner and Suddarth Textbook of Medical Surgical Nursing (12th ed.).", Philadelphia: Lippincott Williams \& Wilkins, 2010. 